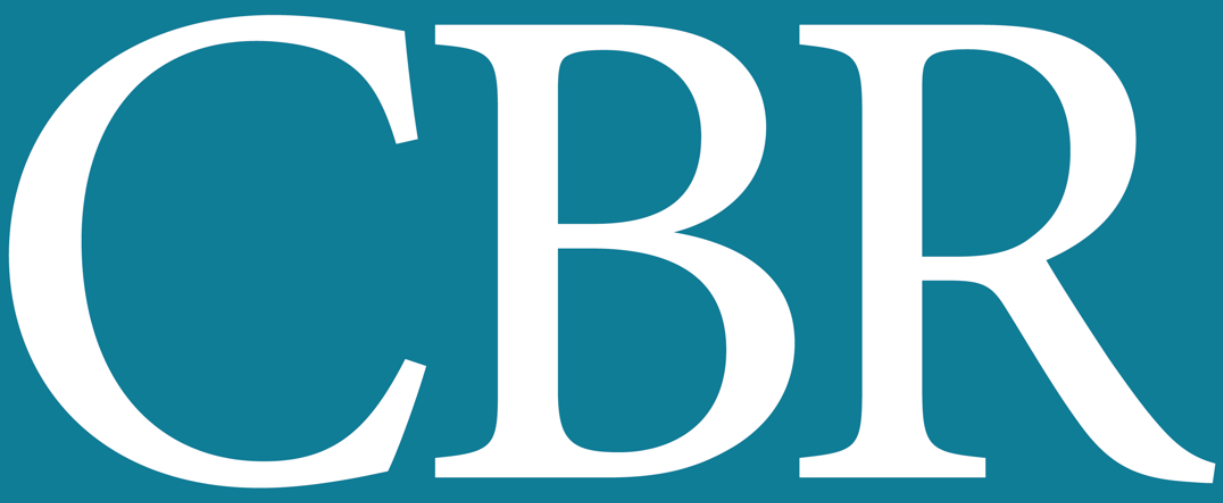

INTERNATIONAL JOURNAL OF CANCER AND BIOMEDICAL RESEARCH

https://jcbr.journals.ekb.eg

Editor-in-chief

Prof. Mohamed Labib Salem, PhD

Fibronectin, but not laminin, expression is associated with favorable outcomes in breast cancer patients

Mohamed S.A. El-Gerbed, Aml Talaat, Karolin A. Abdul-Aziz, Ahmad M. Shalaby, Rasha A Khedr, Mohamed L. Salem and Mohamed Kamal 


\title{
Fibronectin, but not laminin, expression is associated with favorable outcomes in breast cancer patients
}

\author{
Mohamed S.A. El-Gerbed ${ }^{1}$, Aml Talaat ${ }^{1}$, Karolin A. Abdul-Aziz ${ }^{1}$, Ahmad M. Shalaby, ${ }^{2,3}$, Rasha A Khedr ${ }^{4}$, \\ Mohamed L. Salem ${ }^{5}$ and Mohamed Kamal ${ }^{6,7}$ \\ ${ }^{1}$ Department of Zoology, Faculty of Science, University of Damanhour, Egypt \\ ${ }^{2}$ Department of Oncologic Pathology, Damanhour National Cancer Institute, Egyptian Ministry of Health, Egypt \\ ${ }^{3}$ Pathology Department, Faculty of Medicine, Nagasaki University, Japan \\ ${ }^{4}$ Department of Clinical Oncology, Faculty of Medicine, Tanta University, Egypt \\ ${ }^{5}$ Department of Zoology, Faculty of Science, Tanta University, Egypt \\ ${ }^{6}$ Department of Zoology, Faculty of Science, Benha University, Egypt \\ ${ }^{7}$ Department of Stem Cell Biology and Regenerative Medicine, University of Southern California, USA
}

ABSTRACT

ARTICLE INFO

Background: The biology of breast cancer was shown to vary in different ethnic populations. Fibronectin (FN) and laminin (LN) are adhesive glycoproteins present in the extracellular matrix (ECM) and have been shown to associate with prognosis of breast cancer patients. However, their prognostic values have not been fully studied. Aim: We aim to study the prognostic values of FN and LN in breast cancer patients. Materials and Methods: Here, we used immunohistochemical (IHC) staining to investigate the expression patterns of FN and LN in 77 breast cancer patients and to evaluate their prognostic values. Results: High expression levels of FN and $L N$ were detected in $72.7 \%$ and $67.5 \%$ of cases, respectively. High FN expression was associated with longer overall survival (OS) and disease-free survival (DFS). Moreover, multivariate analysis showed that FN is an independent prognostic factor for OS and DFS. No significant associations detected between LN expression and clinicopathological parameters or survival data. Conclusion: Our results suggest that FN and LN biomarkers biologically function differently in breast cancer.

Keywords: Breast cancer; Fibronectin; immunohistochemistry; Laminin; Prognostic marker

Editor-in-Chief: Prof. M.L. Salem, PhD - Article DOI: 10.21608/jcbr.2021.63387.1176

Article history

Received: February 15, 2021

Revised: June 20, 2021

Accepted: October 3, 2021

Correspondence to

Mohamed Kamal,

Norris Research Tower,

1441 Eastlake Ave,

Los Angeles, CA 90033, USA

Email:m.kamal@fsc.bu.edu.eg

Copyright

(c)2021 M El-Gerbedet al.. This is an Open Access article distributed under the Creative Commons Attribution License, which permits unrestricted use, distribution, and reproduction in any medium, provided the original work is properly cited.

\section{INTRODUCTION}

Breast cancer $(\mathrm{BC})$ is a leading cause of cancer death among women in developing countries, despite advances in early detection and treatment (Greco, 2019). Incidence of BC remains highest in more developed regions, but mortality is higher in less developed countries due to lack of early detection and poor prognosis (Mohamed and Elamin, 2020). Some reports showed that the biology of breast cancer differs among ethnic groups (Amend et al., 2006; Field et al., 2012). Most treatment modalities currently used in the clinic have been developed and validated using patients from developed countries, this explains the poor efficacy of these regimens in managing breast cancer in developing countries. Therefore, understanding the biology and pathology of breast cancer should be done in a populationspecific manner.

FN and LN are adhesive glycoprotein and represent major extracellular matrix (ECM) components (Domogatskaya et al., 2012). FN and $L N$ are expressed in cancer by both cancerassociated fibroblasts (CAFs) and cancer cells themselves and their expressions are deregulated in breast cancer (Insua-Rodríguez and Oskarsson, 2016; loachim et al., 2002; Mori et al., 2011). FN is involved in cell proliferation, adhesion, wound healing, blood coagulation, host defense, embryonic development, and oncogenic transformation, migration, differentiation and survival (Kim et al., 2013). 
$\mathrm{LN}$ is playing a key role in cancer cell migration and invasion (Van Der Zee et al., 2012) and was found up-regulated in invasive cancer cells, as well as in the capillaries of invading carcinomas (Mori et al., 2011).

FN and LN have been shown to correlate with cancer patients' prognoses. FN expression was positively correlated with lymph node involvement, Ki-67 and stromal cluster of differentiation expression(Ioachim et al., 2002). Moreover, survival analysis showed an increased mortality risk associated with a high level of FN expression (loachim et al., 2002). Altered LN expressions were found associated with higher sensitivity to recurrence after surgery in pancreatic and head cancers (Van Der Zee et al., 2012) and correlate with poor prognosis in breast cancer (Mori et al., 2011). Although racial variation is profound in the biology of breast cancer, very few studies investigated the biological roles or the prognostic values of $\mathrm{LN}$ or $\mathrm{FN}$ in breast cancer in African populations.

In this study, we aim to investigate the expression patterns and evaluate the prognostic values of $\mathrm{FN}$ and $\mathrm{LN}$ in breast tumors from Egyptian patients.

\section{MATERIALS AND METHODS Patients and tumor characteristics}

After obtaining ethical approval from the Research Ethics Committee, Faculty of Medicine, University of Tanta (Code: 3012/01/15), Formalin-fixed ParaffinEmbedded (FFPE) blocks from 77 breast cancer cases were retrieved from the pathological archive of the Tanta teaching hospital. Clinical history and tumors' characteristics (age, tumor histological type, size, grade, stage, lymph node status (Table 1) and Overall Survival (OS) and Disease-Free Survival (DFS) were available. Overall survival was defined as the time (months) from primary surgical treatment to the time of death from breast cancer. DFS was defined as the interval (months) from primary surgical treatment to the first loco-regional or distant recurrence.

\section{Preparation of histological sections}

Breast cancer tissues were fixed in $10 \%$ buffered formalin for 12-24 hours. A standard method for dehydration, clearing in xylene, and paraffin embedding (melting point $56{ }^{\circ} \mathrm{C}$ ) was used. Sections of 4-micron thickness were cut using a rotary microtome Leitz 1512 (Leitz, Wetzlar, Germany) and stained with hematoxylin and eosin(Bancroft and Cook, 1994).

\section{Immunohistochemical (IHC) analysis}

Tissue microarray's sections were de-waxed in xylene for 10 minutes ( $\mathrm{min}$ ), rehydrated in a descending series of alcohols. Endogenous peroxidase activity was blocked in $3 \% \mathrm{H}_{2} \mathrm{O}_{2}$ for $20 \mathrm{~min}$ at room temperature (RT). Sections were then rinsed in tap water. Antigen retrieval was carried out in $0.1 \%$ trypsin solution at $37^{\circ} \mathrm{C}$ for 15 min for FN, whereas for $\mathrm{LN}$, it was done by immersing the slides in EDTA (PH 9) in the microwave for $25 \mathrm{~min}$. Sections were then washed with phosphate buffer saline (PBS) (3 times, $4 \mathrm{~min} /$ each) and incubated with anti-FN antibody (EP5) at 1 in 50 dilutions (dil) (Santa Cruz Biotechnology, Texas, USA) or anti-LN $\beta-1$ antibody (D-9) at 1:50 dil (Sant Cruz Biotechnology) for 16 hours at $40{ }^{\circ} \mathrm{C}$. Primary antibodies were then washed off using Tris Buffered Saline (TBS) solution (3 times, 4 min/each). Goat anti-mouse horseradish peroxidase (HRP) conjugated secondary antibody (Sant Cruz Biotechnology) at a 1:100 dilution was applied to the sections for $45 \mathrm{~min}$ at RT. Bound antibodies were detected using 3 , 3'- diaminobenzine (DAB) substrate solutions (Vector Laboratories, Burlingame, USA). Slides were then washed with distilled water ( 3 times, $4 \mathrm{~min} /$ each) and counterstained in Mayer's hematoxylin (Sigma-Aldrich, St Louis Mo, USA). Sections were then dehydrated in an ascending series of ethanol $50 \%, 70 \%$ and $100 \%$ for $3 \mathrm{~min}$ at each step then cleared in xylene twice for 3 min/each and were then mounted in DPX medium and covered with a glass coverslip. Negative controls (slides with omitted primary antibodies) and positive controls (tissues known to have high expression of the marker) were used in each batch of staining.

\section{Scoring}

Sections were scored blindly by two personnel and discordant samples were re-scored jointly by the two investigators until they reach a consensus. Samples were categorized into "low" or "high" based on the expression level of 
each marker. Samples that showed any level of expression were categorized as "high", whereas samples that didn't show any level of expression were categorized as "low". Staining intensities were also quantified in "low" and "high" samples using ImageJ (Schneider et al., 2012).

\section{Statistics}

Mean and standard deviation were expressed for numerical data. Based on data distribution (tested by Shapiro-Wilk test), student T-test was used if data were normally distributed, whereas Chi-square was used if data were not normally distributed. Correlation between FN and LN expressions and correlations between FN or LN expression and patients' clinical parameters were tested. Kaplan-Meier was used for estimating survival and log-rank test for comparing survival curves. Cox regression models were used to confirm the Kaplan-Meier results. A multivariable Cox regression model was performed to test whether $\mathrm{FN}$ or $\mathrm{LN}$ are independent prognostic factors. All tests were two-sided and $P$-value $<0.05$ was considered statistically significant. All statistical tests were done using SPSS software version 20.

\section{RESULTS}

\section{Patients' characteristics}

This study includes paraffin blocks of a total of 77 breast tumors. FN and LN IHC staining was performed for all patients' samples. Clinical history and tumor characteristics (age, size, histological type, grade, and lymph node status, Stage, ER, PR, HER2, OS and DFS) were available. Some tumor samples contain normal ducts (Figure $1 \mathrm{~A})$, samples included tumors from different histological types including Invasive lobular carcinoma (Figure 1B) and Invasive ductal carcinoma (Figure $1 \mathrm{C}$ ). Tumor grade $(\mathrm{G})$ ranged from $\mathrm{GI}$ to GIII and samples were dichotomized into two groups; low grade (G I \& II) (Fig.1C) and high grade (G III) (Figure 1D). The distribution of tumor grade, stage and other clinical parameters are presented in Table 1.

\section{Protein expression of $\mathrm{FN}$ in breast cancer}

Seventy-Seven FFPE sections of breast tumors were stained for $\mathrm{FN}$ and the $\mathrm{FN}$ level of expression and distribution in the tissue were evaluated. Sections were incubated with PBS instead of FN primary antibody served as negative controls
(Figure 2A). High FN expression was identified in $56 / 77$ (72.7\%) cases. Positive FN expression is shown in intraductal carcinoma-in-situ and invasive ductal breast carcinoma. Most cases showed high levels of $\mathrm{FN}$ expression in the basement membrane (Figure 2B), nucleus (Figure. $2 B, C, D$ ) and in connective tissue stroma (Figure 2C). Adjacent blood vessels showed strong positive $\mathrm{FN}$ staining in most cases and served as an internal control (Fig. 2C). NIH ImageJ software was used to quantify the intensity of FN expression in breast sections. Samples were classified into "high" and "low" based on their FN intensity. LSD post hoc test showed a significant difference in FN expression between high and low samples $(p<0.05)$ (Figure 2E).

\section{Protein expression of $L N$ in breast tumors}

Seventy-Seven FFPE sections of breast tumors were stained for $\mathrm{LN}$ using $\mathrm{IHC}$ and $\mathrm{LN}$ expression and distribution in the tissue were evaluated. Sections were incubated with PBS instead of LN primary antibody were used as negative controls (Figure 3A). High LN expression was identified in $67.5 \%(52 / 77)$ cases. Some cases showed positive $\mathrm{LN}$ expression in intraductal carcinoma in-situ (Figure 3B,C) and invasive ductal breast carcinoma (Figure 3D). We also observed high levels of $\mathrm{LN}$ expression in the nuclei (Figure 3B,C,D). intensity of $\mathrm{LN}$ expression was quantified using NIH Image software and LSD post hoc test showed a significant increase in LN expression in "high" compared to "low" samples ( $p<0.05$ ) (Figure $3 E$ ).

High FN expression, but not LN, correlates with age at diagnosis, and tumor grade and size

FN expression showed significant associations with age at diagnosis, tumor grade and size (Table 2). The mean of patient's age at diagnosis in patients with high $\mathrm{FN}$ expression was $53.24 \pm$ 10.5 vs. $46 \pm 8.8$ in patients with low FN expression $(p<0.01)$. Moreover, high FN expression was significantly associated with low tumor grade $(p<0.03)$. Approximately $88.2 \%$ $(15 / 17)$ of patients with high FN expression had lower tumor grade compared to $11.8 \%(2 / 17)$ in those with high tumor grade (grade 3 ). In addition, high expression of FN was associated with large tumor size $(3.6 \pm 2.04$ vs. $2.29 \pm 0.58$, $p<0.001)$. There was no significant correlation between LN expression and any of the 
clinicopathological variables either as a continuous or dichotomized variable (Table 2).

\section{High FN expression, but not $\mathrm{LN}$, is associated with longer OS and DFS}

Kaplan-Meier curves showed that high FN expression was significantly associated with longer OS, with an estimated median OS of 53 months (95\% Cl: 44.5-61.6) as compared to 31 months (95\% Cl: $25.7-36.5)$ in patients with low FN expression ( $p=0.001$ ) (Figure 4A). Moreover, high FN expression was significantly associated with longer DFS, with an estimated median DFS of 36 months (95\% Cl: 29.8-40.2) compared to 24 months (95\% Cl: 19.5-30.4) in patients with low FN expression ( $p=0.013$ ) (Figure 4B). On the other hand, there was no significant association between LN expression and either OS or DFS. The estimated median OS in patients with high LN expression was 44 months $(95 \% \mathrm{Cl}$ : $37.2-$ 51.4) compared to 49 months (95\% Cl: $36.3-$ $61.5)$ in patients with low LN staining $(p=0.61)$ (Figure $4 \mathrm{C}$ ); and the estimated median DFS of patients with high LN expression was 30 months (95\% Cl: 26.2-33.4) compared to 34 months (95\% Cl: 25.7-41.6) in patients with low LN expression $(p=0.41)$ (Figure 4D).

\section{$\mathrm{FN}$, but not $\mathrm{LN}$, expression is an independent prognostic factor for OS and DFS}

A Cox univariate regression model was performed to test the association between FN and/or LN with patients' survival. Univariate analysis for OS showed significant association with FN (HR=0.36, 95\% Cl: 0.19-0.69, $p=0.002$ ). Moreover, DFS showed statistically significant association with $\mathrm{FN}(\mathrm{HR}=0.46,95 \% \mathrm{Cl}: 0.24-0.87$, $p=0.017$ ) (Table 3). We then performed a multivariate Cox regression model to test whether $\mathrm{FN}$ and/or $\mathrm{LN}$ are independent prognostic factor/s. Correlations between FN and OS or DFS were analyzed in relation to age, size, tumor grade, histological type, ER, PR, and HER2. FN expression appeared to be an independent prognostic factor for both OS ( $\mathrm{HR}=0.33,95 \% \mathrm{Cl}: 0.15-0.72, \mathrm{p}=0.005$ ) (Table 3) and DFS (HR $=0.27,95 \% \mathrm{Cl}: 0.12-0.61, p=0.001)$ (Table 4).

Applying all the above correlative studies, including univariate or multivariate analyses on
LN, we did not find any significant correlation between $\mathrm{FN}$ expression and patient survival (Tables 3 and 4).

\section{DISCUSSION}

Taking into considerations the reported racial variation in the biology of breast cancer, this is the first study to evaluate the prognostic values of $F N$ and $L N$ in breast cancer patients in Egypt. In 77 breast cancer Egyptian patients, high FN expression was shown in $72.7 \%$ of cases which agrees with other studies reported that $F N$ is overexpressed in breast and colorectal cancers.

In our study, a direct correlation was found between the high expression level of FN and the age of patient at diagnosis. Indeed, this observation disagrees with previous studies, which showed no significant correlation between FN expression and age (Bae et al., 2013; Swiatoniowski et al., 2005; Yi et al., 2016). Similarly, we found that the high level of FN expression is associated with favorable patients' outcome including association with low histological grade and longer OS and DFS. These correlations partially agree with the findings of Swiatoniowski et al. (2005) who found that FN expression is associated with low tumor grade however, their study indicated a lack of relationship between FN expression and prognosis (Swiatoniowski et al., 2005). More paradoxically, our findings are in contrast to other studies reported significant correlations between $\mathrm{FN}$ and patients' poor prognosis (Bae et al., 2013; Fernandez-Garcia et al., 2014).

These contradictions could be because of the different site of expression of $\mathrm{FN}$ we recorded in our patients. In the above-mentioned studies, $\mathrm{FN}$ was expressed in the stroma and or tumor cells, whereas in our study we evaluated only tumor cell expression of the markers. Indeed, functional studies found that FN has a protumoral effects by organizing cancer cells to promote invasion and metastasis by serving as a scaffold extended outwards in many different directions to guide cancer cells outside of the primary tumor (Rick et al., 2019). Interestingly, FN deposited in the tumor microenvironments promotes tumor progression but is paradoxically related to a better prognosis (Lin et al., 2020). 
Table 1. Patient characteristics in breast cancer

\begin{tabular}{|c|c|c|c|}
\hline Variables & No. of Patients (\%) & Variables & No. of Patients (\%) \\
\hline $\begin{array}{l}\text { Age } \\
\text { Mean } \\
\text { Range } \\
\text { Grade } \\
\text { G1 } \\
\text { G2 } \\
\text { G3 } \\
\text { Missing } \\
\text { Grade distribution } \\
\text { Low (1,2) } \\
\text { High (3) } \\
\text { Missing } \\
\text { Tumor size } \\
\text { Mean } \\
\text { Range } \\
\text { Stage } \\
0 \\
1 \\
2 \\
3 \\
\text { Missing }\end{array}$ & $\begin{array}{l}51.26 \\
31-73 \\
4(5.2) \\
38(49.4) \\
20(26) \\
15(19.5) \\
42(54.5) \\
20(26) \\
15(19.5) \\
3.25 \\
1-9 \\
3(3.9) \\
2(2.6) \\
20(26) \\
9(11.7) \\
43(55.8)\end{array}$ & $\begin{array}{l}\text { Histological type } \\
\text { In situ carcinoma } \\
\text { Invasive ductal carcinoma } \\
\text { Invasive lobular carcinoma } \\
\text { Missing } \\
\text { ER } \\
\text { Negative } \\
\text { Positive } \\
\text { Missing } \\
\text { PR } \\
\text { Negative } \\
\text { positive } \\
\text { Missing } \\
\text { HER2 } \\
\text { Negative } \\
\text { Positive } \\
\text { Missing } \\
\text { Number of Lymph nodes } \\
\text { Mean } \\
\text { Range }\end{array}$ & $\begin{array}{l}6(7.8) \\
53(68.8) \\
3(3.9) \\
15(19.5) \\
17(22.1) \\
45(58.4) \\
15(19.5) \\
29(37.7) \\
33(42.9) \\
15(19.5) \\
50(64.9) \\
12(15.6) \\
43(19.5) \\
9.46 \\
2-21\end{array}$ \\
\hline
\end{tabular}

Table 2. Patient characteristics according to FN and LN expression in breast cancer

\begin{tabular}{|c|c|c|c|c|c|c|}
\hline & \multicolumn{3}{|c|}{ FN } & \multicolumn{3}{|c|}{ LN } \\
\hline & Low & High & $\begin{array}{c}P \\
\text { value }\end{array}$ & Low & High & P value \\
\hline \multicolumn{7}{|c|}{ Age $n,($ Mean \pm SEM) } \\
\hline $31-73$ & $17(46 \pm 8.8)$ & $45(53.24 \pm 10.5)$ & 0.01 & $21(51.57 \pm 11.46)$ & $41(51.1 \pm 10.26)$ & 0.87 \\
\hline \multicolumn{7}{|l|}{ Size } \\
\hline $1-9$ & $17(2.29 \pm 0.58)$ & $45(3.6 \pm 2.04)$ & 0.001 & $21(3.53 \pm 1.86)$ & $41(3.1 \pm 1.86)$ & 0.39 \\
\hline \multicolumn{7}{|c|}{ Lymph node $n,($ Mean \pm SEM) } \\
\hline $2-21$ & $1(16)$ & $27(9.22)$ & 0.27 & $14(9.36)$ & $14(9.57)$ & 0.92 \\
\hline \multicolumn{7}{|c|}{ Grade distribution $\mathrm{n},(\%)$} \\
\hline $\operatorname{Low}(1,2)$ & $15(88.2)$ & $27(60)$ & \multirow[b]{2}{*}{0.03} & $14(66.7)$ & $28(68.3)$ & \multirow[b]{2}{*}{0.89} \\
\hline High (3) & $2(11.8)$ & $18(40)$ & & $7(33.3)$ & $13(31.7)$ & \\
\hline \multicolumn{7}{|c|}{ Stage $n,(\%)$} \\
\hline 0 & $1(6.2)$ & $2(11.1)$ & \multirow{4}{*}{0.50} & $1(14.3)$ & $2(7.4)$ & \multirow{4}{*}{0.67} \\
\hline 1 & 0 & $2(11.1)$ & & 0 & $2(7.4)$ & \\
\hline 2 & $10(62.5)$ & $10(55.6)$ & & $5(71.4)$ & $15(55.6)$ & \\
\hline 3 & $5(31.2)$ & $4(22.2)$ & & $1(14.3)$ & $8(29.6)$ & \\
\hline \multicolumn{7}{|c|}{ Histological type $* n,(\%)$} \\
\hline $\mathrm{CIS}$ & $3(17.7)$ & $3(6.6)$ & \multirow{3}{*}{0.61} & $3(15.4)$ & $4(9.8)$ & \multirow{3}{*}{0.68} \\
\hline IDC & $13(76.5)$ & $40(88.9)$ & & $18(85.7)$ & $35(85.4)$ & \\
\hline ILC & $1(5.9)$ & $2(4.4)$ & & $1(4.8)$ & $2(4.9)$ & \\
\hline \multicolumn{7}{|l|}{ ER n, (\%) } \\
\hline Negative & $5(29.4)$ & $12(26.7)$ & \multirow[b]{2}{*}{0.82} & $7(33.3)$ & $10(24.4)$ & \multirow{2}{*}{0.45} \\
\hline Positive & $12(70.6)$ & $33(73.3)$ & & $14(66.7)$ & $31(75.6)$ & \\
\hline \multicolumn{7}{|l|}{ PR n, (\%) } \\
\hline Negative & $6(35.3)$ & $23(51.1)$ & \multirow[b]{2}{*}{0.26} & $11(52.4)$ & $18(43.9)$ & \multirow{2}{*}{0.26} \\
\hline Positive & $11(64.7)$ & $22(48.9)$ & & $10(47.6)$ & $23(56.1)$ & \\
\hline \multicolumn{7}{|c|}{ HER2 n, (\%) } \\
\hline Negative & $14(82.4)$ & $36(80)$ & \multirow[b]{2}{*}{0.83} & $18(35.7)$ & $32(78)$ & \multirow[b]{2}{*}{0.47} \\
\hline Positive & $3(17.6)$ & $9(20)$ & & $3(14.3)$ & $9(22)$ & \\
\hline
\end{tabular}

* CIS = carcinoma in-situ, IDC = invasive ductal carcinoma, ILC= invasive lobular carcinoma 
Table 3. Univariate and multivariate analyses of overall survival to examine the prognostic effect of FN and LN

\begin{tabular}{|c|c|c|c|c|c|c|c|c|}
\hline \multirow[b]{2}{*}{ Variable } & \multicolumn{4}{|c|}{ FN } & \multicolumn{4}{|c|}{ LN } \\
\hline & $\begin{array}{c}\text { Univariate } \\
\text { (p value) }\end{array}$ & $\begin{array}{c}\text { HR } \\
(95 \% \mathrm{Cl})^{*}\end{array}$ & $\begin{array}{c}\text { Multivariate } \\
\text { (p value) }\end{array}$ & $\begin{array}{c}\text { HR } \\
(95 \% \mathrm{Cl})^{*}\end{array}$ & $\begin{array}{c}\text { Univariate } \\
\text { (p value) }\end{array}$ & $\begin{array}{c}\text { HR } \\
(95 \% \mathrm{Cl})^{*}\end{array}$ & $\begin{array}{c}\text { Multivariate } \\
\text { (p value) }\end{array}$ & $\begin{array}{c}\text { HR } \\
(95 \% \mathrm{Cl})^{*}\end{array}$ \\
\hline Age & 0.34 & $\begin{array}{c}1.01 \\
(0.98-1.04)\end{array}$ & 0.19 & $\begin{array}{c}1.02 \\
(0.99-1.05)\end{array}$ & 0.34 & $\begin{array}{c}1.01 \\
(0.98-1.04)\end{array}$ & 0.30 & $\begin{array}{c}1.01 \\
(0.98-1.04)\end{array}$ \\
\hline Size & 0.09 & $\begin{array}{c}0.84(0.69- \\
1.03)\end{array}$ & 0.11 & $\begin{array}{c}0.82(0.65- \\
1.04)\end{array}$ & 0.09 & $\begin{array}{c}0.84 \\
(0.69-1.03)\end{array}$ & 0.02 & $\begin{array}{c}0.78 \\
(0.62-0.97)\end{array}$ \\
\hline \multicolumn{9}{|c|}{ Grade distribution } \\
\hline Low vs High & 0.85 & $\begin{array}{c}1.02 \\
(0.75-1.39)\end{array}$ & 0.54 & $\begin{array}{c}1.13 \\
(0.76-1.68)\end{array}$ & 0.85 & $\begin{array}{c}1.02 \\
(0.75-1.39)\end{array}$ & 0.86 & $\begin{array}{c}1.03 \\
(0.71-1.49)\end{array}$ \\
\hline \multicolumn{9}{|c|}{ Histological type } \\
\hline $\begin{array}{l}\text { CIS vs IDC vs } \\
\text { ILC** }\end{array}$ & 0.57 & $\begin{array}{c}0.86 \\
(0.52-1.43)\end{array}$ & 0.93 & $\begin{array}{c}1.02 \\
(0.60-1.74)\end{array}$ & 0.57 & $\begin{array}{c}0.86 \\
(0.52-1.43)\end{array}$ & 0.44 & $\begin{array}{c}0.81 \\
(0.47-1.39)\end{array}$ \\
\hline \multicolumn{9}{|l|}{ ER } \\
\hline $\begin{array}{l}\text { Negative vs } \\
\text { Positive }\end{array}$ & 0.35 & $\begin{array}{c}1.37 \\
(0.69-2.71)\end{array}$ & 0.30 & $\begin{array}{c}1.47 \\
(0.71-3.04)\end{array}$ & 0.35 & $\begin{array}{c}1.37 \\
(0.69-2.71)\end{array}$ & 0.46 & $\begin{array}{c}1.31 \\
(0.63-2.72)\end{array}$ \\
\hline \multicolumn{9}{|l|}{ PR } \\
\hline $\begin{array}{l}\text { Negative vs } \\
\text { Positive }\end{array}$ & 0.51 & $\begin{array}{c}1.12 \\
(0.67-2.17)\end{array}$ & 0.85 & $\begin{array}{c}1.06 \\
(0.51-2.20)\end{array}$ & 0.51 & $\begin{array}{c}1.12 \\
(0.67-2.17)\end{array}$ & 0.25 & $\begin{array}{c}1.48 \\
(0.75-2.93)\end{array}$ \\
\hline \multicolumn{9}{|l|}{ HER2 } \\
\hline $\begin{array}{l}\text { Negative vs } \\
\text { Positive }\end{array}$ & 0.41 & $\begin{array}{c}0.72 \\
(0.33-1.55)\end{array}$ & 0.20 & $\begin{array}{c}0.59 \\
(0.26-1.33)\end{array}$ & 0.41 & $\begin{array}{c}0.72 \\
(0.33-1.55)\end{array}$ & 0.30 & $\begin{array}{c}0.66 \\
(0.30-1.44)\end{array}$ \\
\hline \multicolumn{9}{|l|}{ FN / LN } \\
\hline High vs low & 0.002 & $\begin{array}{c}0.36 \\
(0.19-0.69)\end{array}$ & 0.005 & $\begin{array}{c}0.33 \\
(0.15-0.72)\end{array}$ & 0.62 & $\begin{array}{c}1.16 \\
(0.62-2.16)\end{array}$ & 0.58 & $\begin{array}{c}1.19 \\
(0.63-2.25)\end{array}$ \\
\hline
\end{tabular}

Multivariate analysis: $\mathrm{n}=77$, event $=46$, censored $=16$, missing $=15, * \mathrm{HR}=$ Hazard ratio and $\mathrm{Cl}=$ confidence interval, $* * \mathrm{ClS}=\mathrm{carcinoma}$ in-situ, IDC $=$ invasive ductal carcinoma, ILC= invasive lobular carcinoma, Bold = statistically significant

Table 4. Univariate and multivariate analysis of disease-free survival to examine the prognostic effect of FN and LN

\begin{tabular}{|c|c|c|c|c|c|c|c|c|}
\hline \multirow[b]{2}{*}{ Variable } & \multicolumn{4}{|c|}{ FN } & \multicolumn{4}{|c|}{ LN } \\
\hline & $\begin{array}{l}\text { Univariate } \\
\text { ( } p \text { value) }\end{array}$ & $\begin{array}{c}\text { HR } \\
(95 \% \mathrm{Cl})^{*}\end{array}$ & $\begin{array}{l}\text { Multivariate } \\
\text { ( } p \text { value) }\end{array}$ & $\begin{array}{c}\text { HR } \\
(95 \% \mathrm{Cl})^{*}\end{array}$ & $\begin{array}{l}\text { Univariate } \\
\text { ( } p \text { value) }\end{array}$ & $\begin{array}{c}\text { HR } \\
(95 \% \mathrm{Cl})^{*}\end{array}$ & $\begin{array}{l}\text { Multivariate } \\
\text { ( } p \text { value) }\end{array}$ & $\begin{array}{c}\text { HR } \\
(95 \% \mathrm{Cl})^{*}\end{array}$ \\
\hline Age & 0.06 & $\begin{array}{c}1.02 \\
(0.99-1.06)\end{array}$ & 0.21 & $\begin{array}{c}1.02 \\
(0.98-1.05)\end{array}$ & 0.06 & $\begin{array}{c}1.02 \\
(0.99-1.06)\end{array}$ & 0.28 & $\begin{array}{c}1.01 \\
(0.98-1.05)\end{array}$ \\
\hline Size & 0.28 & $\begin{array}{c}1.11 \\
(0.91-1.34)\end{array}$ & 0.27 & $\begin{array}{c}1.13 \\
(0.90-1.41)\end{array}$ & 0.28 & $\begin{array}{c}1.11 \\
(0.91-1.34)\end{array}$ & 0.77 & $\begin{array}{c}1.02 \\
(0.84-1.26)\end{array}$ \\
\hline \multicolumn{9}{|c|}{ Grade distribution } \\
\hline Low vs High & 0.02 & $\begin{array}{c}1.4 \\
(1.05-1.96)\end{array}$ & 0.03 & $\begin{array}{c}1.50 \\
(1.02-2.22)\end{array}$ & 0.02 & $\begin{array}{c}1.4 \\
(1.05-1.96)\end{array}$ & 0.18 & $\begin{array}{c}1.27 \\
(0.89-1.82)\end{array}$ \\
\hline \multicolumn{9}{|c|}{ Histological type } \\
\hline $\begin{array}{l}\text { CIS vs IDC vs } \\
\text { ILC** }\end{array}$ & 0.91 & $\begin{array}{c}0.97 \\
(0.61-1.54)\end{array}$ & 0.76 & $\begin{array}{c}1.08 \\
(0.64-1.83)\end{array}$ & 0.91 & $\begin{array}{c}0.97 \\
(0.61-1.54)\end{array}$ & 0.44 & $\begin{array}{c}0.81 \\
(0.48-1.38)\end{array}$ \\
\hline \multicolumn{9}{|l|}{ ER } \\
\hline $\begin{array}{l}\text { Negative vs } \\
\text { Positive }\end{array}$ & 0.41 & $\begin{array}{c}1.33 \\
(0.67-2.63)\end{array}$ & 0.86 & $\begin{array}{c}1.06 \\
(0.50-2.26)\end{array}$ & 0.41 & $\begin{array}{c}1.33 \\
(0.67-2.63)\end{array}$ & 0.82 & $\begin{array}{c}0.91 \\
(0.42-1.97)\end{array}$ \\
\hline \multicolumn{9}{|l|}{ PR } \\
\hline $\begin{array}{l}\text { Negative vs } \\
\text { Positive }\end{array}$ & 0.08 & $\begin{array}{c}1.69 \\
(0.93-3.06)\end{array}$ & 0.63 & $\begin{array}{c}1.19 \\
(0.58-2.41)\end{array}$ & 0.08 & $\begin{array}{c}1.69 \\
(0.93-3.06)\end{array}$ & 0.19 & $\begin{array}{c}1.58 \\
(0.79-3.14)\end{array}$ \\
\hline \multicolumn{9}{|l|}{ HER2 } \\
\hline $\begin{array}{l}\text { Negative vs } \\
\text { Positive }\end{array}$ & 0.14 & $\begin{array}{c}0.56 \\
(0.25-1.22)\end{array}$ & 0.08 & $\begin{array}{c}0.49 \\
(0.21-1.10)\end{array}$ & 0.14 & $\begin{array}{c}0.56 \\
(0.25-1.22)\end{array}$ & 0.14 & $\begin{array}{c}0.54 \\
(0.24-1.22)\end{array}$ \\
\hline \multicolumn{9}{|l|}{ FN /LN } \\
\hline High vs low & 0.03 & $\begin{array}{c}0.52 \\
(0.28-0.95)\end{array}$ & 0.001 & $\begin{array}{c}0.27 \\
(0.12-0.61)\end{array}$ & 0.42 & $\begin{array}{c}1.28 \\
(0.69-2.41)\end{array}$ & 0.75 & $\begin{array}{c}1.11 \\
(0.56-2.20)\end{array}$ \\
\hline
\end{tabular}

Multivariate analysis: $\mathrm{n}=77$, event $=46$, censored $=16$, missing $=15, * \mathrm{HR}=$ Hazard ratio and $\mathrm{Cl}=$ confidence interval, $* * \mathrm{CIS}=$ carcinoma in-situ, IDC $=$ invasive ductal carcinoma, ILC= invasive lobular carcinoma, Bold = statistically significant. 

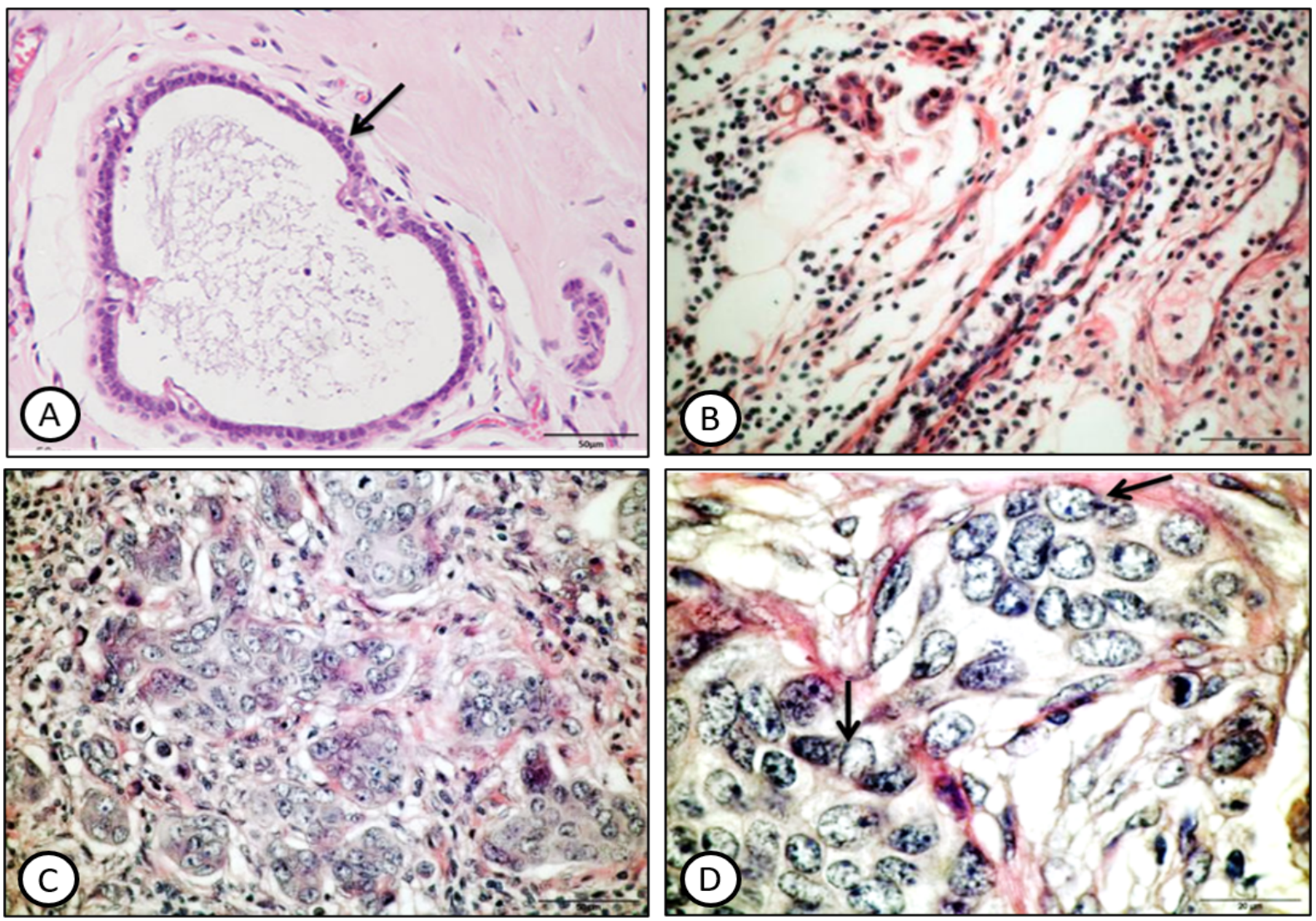

Figure 1. Light micrograph of breast cancer tissues (H \& E-stained) illustrating. A) normal duct (arrow) embedded in connective tissue stroma, B) Invasive lobular carcinoma GI with Vascular emboli. C) Invasive ductal carcinoma GII. D) GIII invasive ductal carcinoma with an abnormal mitotic figure. Scale bare:50 $\mu \mathrm{m}(\mathrm{A}, \mathrm{B}, \mathrm{C})$ and $20 \mu \mathrm{m}(\mathrm{D})$.
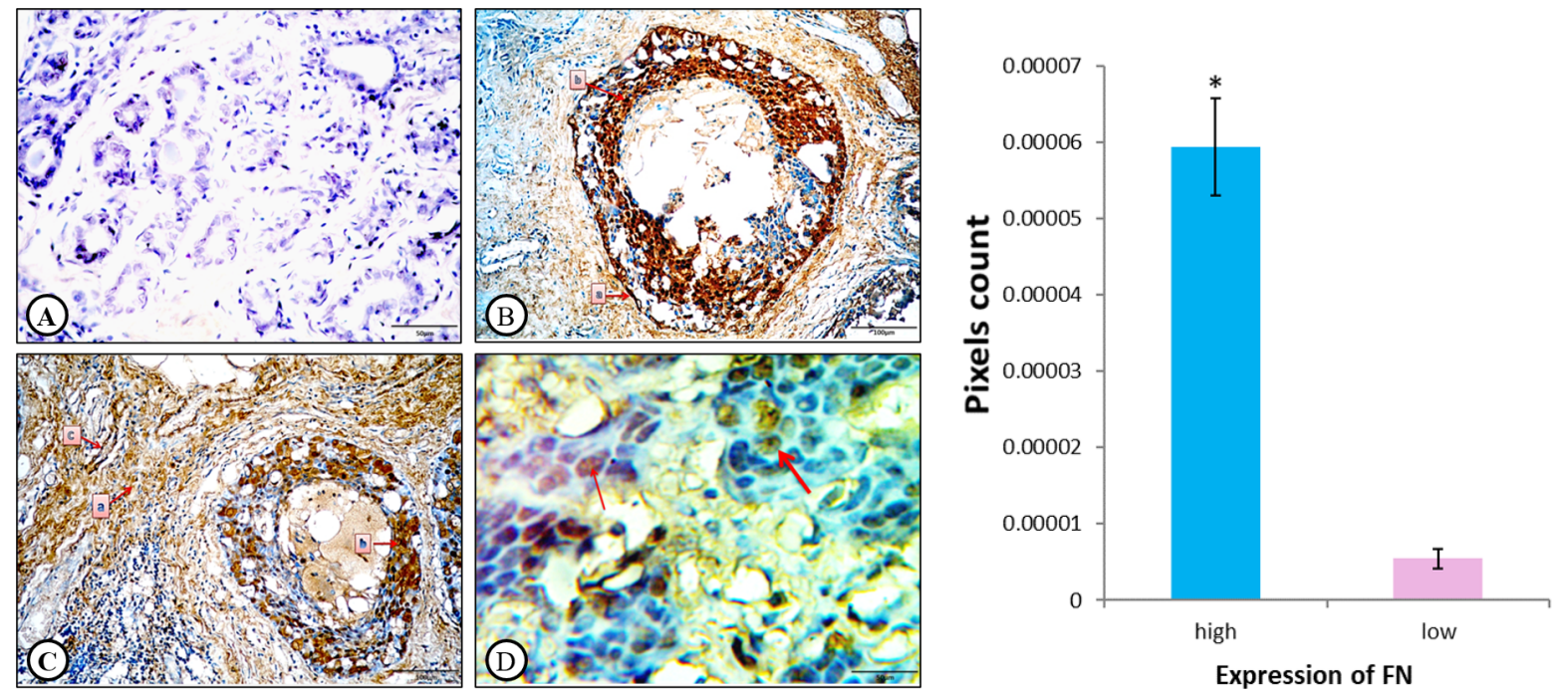

Figure 2. Immunohistochemical staining of FN tissues with breast carcinoma. A) Negative control, where PBS was applied to the sections instead of FN primary antibody. B) Breast Intra-ductal carcinoma Insitu Comedo Variant. a) Tissues showing positive membranous staining (arrow), b) Tissues showing positive nuclear staining (arrow) but the surrounding connective tissue stroma showing low expression. C) Breast Intraductal carcinoma Insitu Comedo Variant. a) High level of FN expression in connective tissue stroma. b) The duct shows positive FN nuclear expression. c) Blood vessels (internal controls) showing positive expression (arrows). D) Breast invasive ductal carcinoma. Tissues showing positive staining in nucleus (arrow).

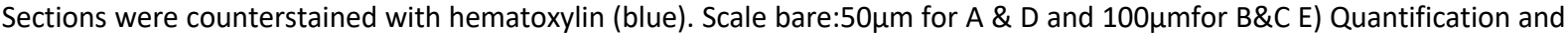
statistical analyses of FN expression (pixels) measured by ImageJ in samples with high and low FN expression. $\left({ }^{*}\right)$ significant increase in samples with "high" compared to "low" FN expression $(p<0.05)$. 

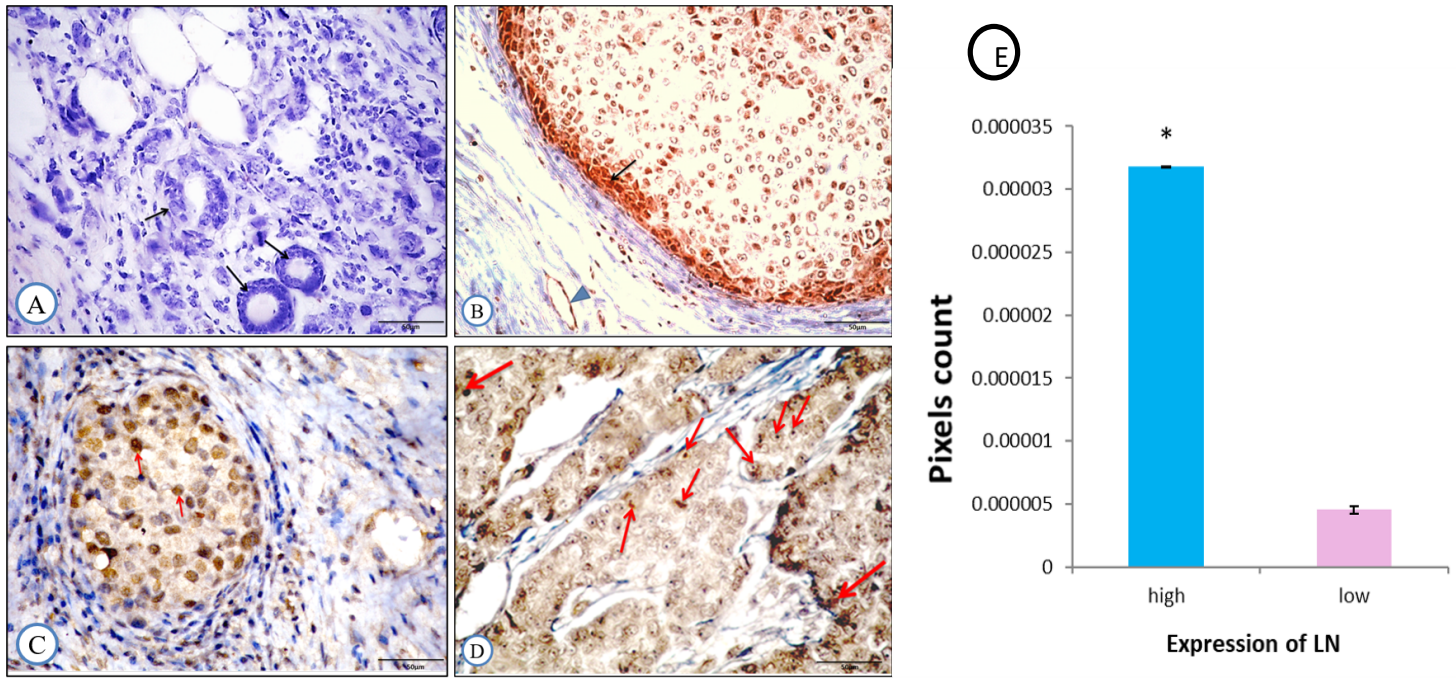

Figure 3. Immunohistochemical staining of LN in breast invasive ductal carcinoma. A) Negative control, where PBS was applied to the sections instead of LN primary antibody. Sections were counterstained with hematoxylin (blue). (arrows). B) Breast Intraductal carcinoma. The duct shows a high level of LN nuclear expression in tumor cells near the plasma membrane (arrow) and blood vessel (internal control) showing positive expression (arrow's head). C) Breast Intraductal carcinoma Insitu solid variant. The duct shows positive expression (arrow). D) Grade III invasive ductal carcinoma showing positive nuclear staining (red arrows). Scale bare: $50 \mu \mathrm{m}$. E) Quantification and statistical analyses of FN expression (pixels) measured by ImageJ in samples with "high" and "low" FN expression. ( $\left.{ }^{*}\right)$ significant increase in samples with "high" compared to "low" FN expression $(p<0.05)$.
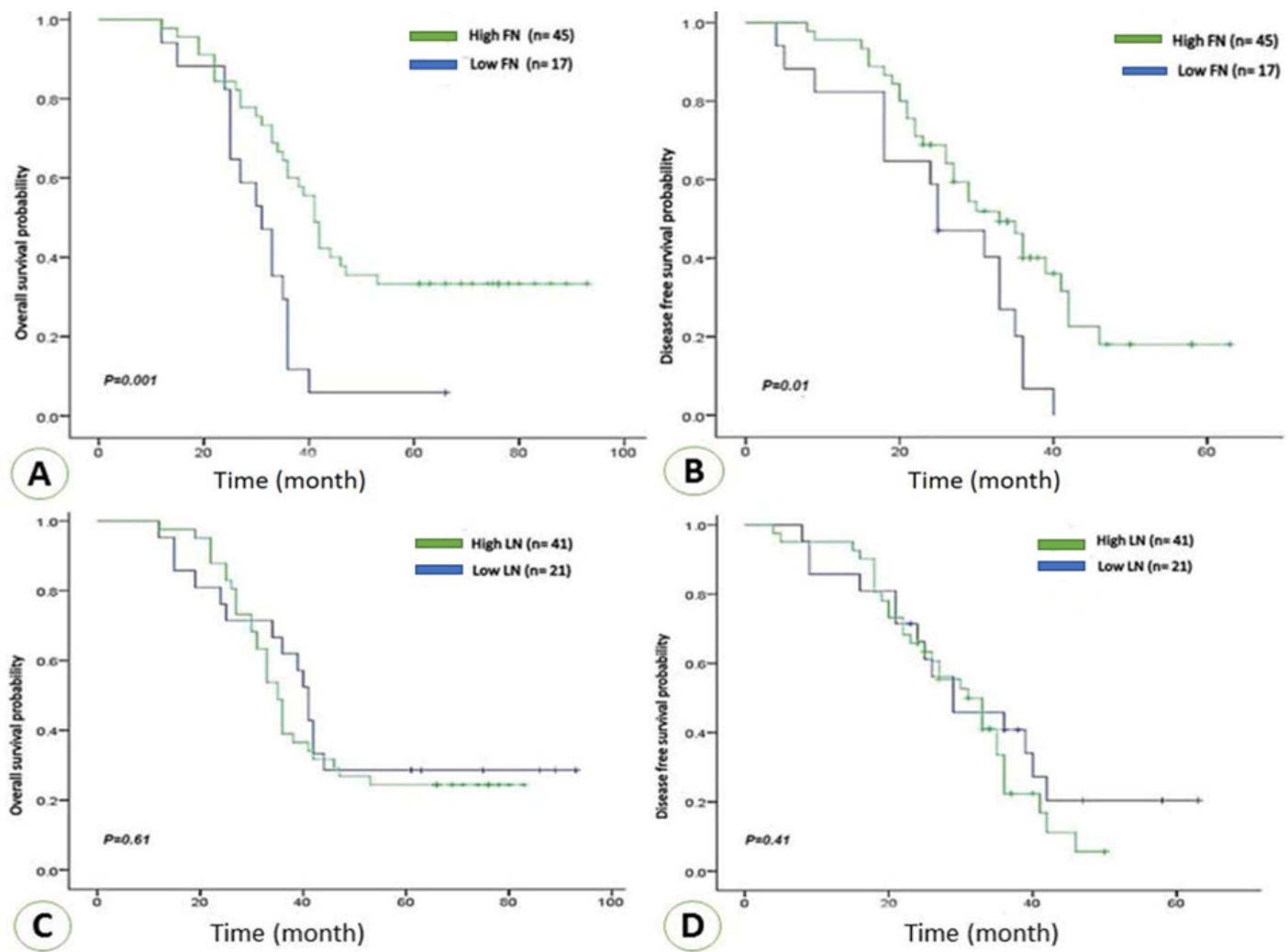

Figure 4. Overall survival and disease-free survival based on FN or LN expression. Kaplan Meir curves compare overall all survival based on FN (A) and LN (C). Kaplan Meir curves compare disease-free survival based on FN (B) and LN (D). 
We recommend more studies with large numbers of patients to investigate the prognostic values of $\mathrm{FN}$ in both cancer cells and stroma.

Moreover, the tumor cell expressions of $\mathrm{FN}$ in the above-mentioned studies were mainly membranous and/or cytoplasmic. In our study, however, FN, and LN, showed both cytoplasmic and membranous staining, where a large proportion of tumor cells showed nuclear staining of both markers. The nuclear staining of FN and/or LN may be due to the development of certain mutation(s) that resulted in the formation of novel isoforms localized to the nuclei. Indeed, further studies are needed to investigate $\mathrm{FN}$ and $\mathrm{LN}$ gene sequences, protein sites of expression and their prognostic values.

A second explanation for the contradiction between our findings and those that showed associations between $\mathrm{FN}$ expression and patients' poor prognosis, could be the racial variations between patients in our study and those of other studies. For example, we used patients from Egypt, whereas Swiatoniowski et al (2005) used patients from Poland (Swiatoniowski et al., 2005) and Bae et al (2013) used patients from South Korea (Bae et al., 2013). A third possibility could be the relatively short follow-up period (5 years) in our study. The final explanation could be due to the small number of patients in our study. As such, a larger confirmatory study is needed to confirm the role of FN and LN in breast cancer patients with different ethnic backgrounds.

Opposite to what we found with FN expression; LN expression did not show any significant association with any of the patients' clinicopathological parameters. This contradicts other studies which showed that a progressive lack of LN is associated with poorly differentiated tumors (Carpenter et al., 2018) which agrees with a functional study revealed that cells with impaired LN adhesion are enriched in genes associated with cell motility and molecular pathways linked to cytokine signaling and inflammation (Todd et al., 2016).

Our study showed no correlation between LN and patients' survival which agrees with those of Rodriguez-Pinilla et al. (2007) who showed that LN expression does not correlate with patients' survival (Rodriguez-Pinilla et al., 2007). In contrast, Ross et al. (2015) reported that LN was associated with poor outcomes in breast cancer patients (Ross et al., 2015). Agboola (2017) also found in Nigerian breast cancer patients that the level of LN expression was associated with poor prognosis but failed to be an independent prognostic factor (Agboola et al., 2016). These inconsistencies could be due to the racial variation, different sites of expression and or study size as discussed above in the case of FN.

We are among the first to report that prognostic values of FN and LN in breast cancer patients from Egypt is different than those from other countries. However, our study suffers from several limitations. First, our patients' cohort was collected from a single center. Egypt is a populous country with over 100 million people from different ethnic origins. Therefore, larger follow-up and multicentric studies covering different ethnic origins in the Egyptian population are highly recommended to fully address the prognostic values of $\mathrm{FN}$ and $\mathrm{LN}$ in Egypt. Another limitation is that our study is a pilot study with a small number of patients to test the hypothesis that FN and or LN may have different prognostic values in Egyptian patients compared to other patients from different ethnic groups. Since the small sample size, we could not investigate $\mathrm{FN}$ and $\mathrm{LN}$ expression and their prognostic values in-lights of breast cancer subtypes, treatment, and patients' response to the drug. Therefore, large confirmatory studies are warranty to evaluate the clinical utility of FN and $L N$ in different disease contexts.

\section{CONCLUSION}

To the best of our knowledge, the present study is the first to compare the FN and LN expression and their prognostic values in Egyptian breast cancer patients and to correlate their expression with the clinicopathological measures. We showed that $\mathrm{FN}$ and $\mathrm{LN}$ are expressed in tumor cells' nuclei, suggesting the presence of population-specific mutations led to the expression of novel protein isoforms localized to the nuclei. This may explain the unexpected prognostic value of FN and LN in our study as compared to other studies. Larger studies with longer follow-up duration are 
needed to confirm the prognostic values of FN and LN in Egyptian patients with breast cancer.

\section{FUNDING}

This study was supported by a research grant no CSSP127 from Library of Alexandria, Egypt and University of Benha, Egypt to MK.

\section{AUTHORS' CONTRIBUTION}

MK proposed and designed the study, AT performed IHC staining, ME imaged samples, MK and AT performed statistical analyses. RAK and AG provided patients materials and clinical information. KAA, AMRS, and MLS reviewed the data. $M K$, and ME wrote the manuscript. The first two authors have contributed equally and all authors reviewed the manuscript.

\section{CONFLICT OF INTEREST}

The authors declare that they have no conflict of interest.

\section{REFERENCES}

Agboola, A, Ayodeji, O, Ebili, E, Henry, O, lyawe, I, Victoria, O, Banjo, B, Adekunbiola, A, Salami, S, and Babatunde, S (2016). Aurora Kinase A Expression in Nigerian Breast Cancer Patients and Correlation with Clinicopathological, Biological and Prognostic Features. African Journal of Science and Nature, 2, 53-64.

Amend, K, Hicks, D, and Ambrosone, CB (2006). Breast cancer in African-American women: differences in tumor biology from EuropeanAmerican women. Cancer Research, 66, 83278330.

Bae, YK, Kim, A, Kim, MK, Choi, JE, Kang, SH, and Lee, SJ (2013). Fibronectin expression in carcinoma cells correlates with tumor aggressiveness and poor clinical outcome in patients with invasive breast cancer. Human Pathology, 44, 20282037.

Bancroft, JD, and Cook, HC (1994). Manual of histological techniques and their diagnostic application (Churchill Livingstone, Edinburgh.).

Carpenter, PM, Ziogas, A, Markham, EM, Cantillep, AS, Yan, R, and Anton-Culver, H (2018). Laminin 332 expression and prognosis in breast cancer. Human Pathology, 82, 289-296.

Domogatskaya, A, Rodin, S, and Tryggvason, K (2012). Functional diversity of laminins. Annual Review of Cell and Developmental Biology, 28, 523-553.
Fernandez-Garcia, B, Eiró, N, Marín, L, GonzálezReyes, S, Gonzalez, LO, Lamelas, ML, and Vizoso, FJ (2014). Expression and prognostic significance of fibronectin and matrix metalloproteases in breast cancer metastasis. Histopathology, 64, 512-522.

Field, LA, Love, B, Deyarmin, B, Hooke, JA, Shriver, $C D$, and Ellsworth, RE (2012). Identification of differentially expressed genes in breast tumors from African American compared with Caucasian women. Cancer, 118, 1334-1344.

Greco, SJ (2019). Breast cancer risk in a rapidly aging population: advances and approaches to study the aging tissue microenvironment. Breast cancer (Dove Medical Press), 11, 111-113.

Insua-Rodríguez, J, and Oskarsson, T (2016). The extracellular matrix in breast cancer. Advanced drug delivery reviews, 97, 41-55.

loachim, E, Charchanti, A, Briasoulis, E, Karavasilis, V, Tsanou, H, Arvanitis, D, Agnantis, NJ, and Pavlidis, N (2002). Immunohistochemical expression of extracellular matrix components tenascin, fibronectin, collagen type IV and laminin in breast cancer: their prognostic value and role in tumour invasion and progression. European Journal of Cancer, 38, 2362-2370.

Kim, D-K, Kang, B, Kim, OY, Choi, D-s, Lee, J, Kim, SR, Go, G, Yoon, YJ, Kim, JH, and Jang, SC (2013). EVpedia: an integrated database of highthroughput data for systemic analyses of extracellular vesicles. Journal of Extracellular Vesicles, 2, 20384.

Lin, T-C, Yang, C-H, Cheng, L-H, Chang, W-T, Lin, Y-R, and Cheng, $\mathrm{H}-\mathrm{C}$ (2020). Fibronectin in cancer: friend or foe. Cells, 9, 27.

Mohamed, KE, and Elamin, A (2020). Adherence to endocrine therapy and its relation to diseasefree survival among breast cancer patients visiting an out-patient clinic at Khartoum Oncology Hospital, Sudan. Journal of Evaluation in Clinical Practice.

Mori, T, Kariya, Y, Komiya, E, Higashi, S, Miyagi, Y, Sekiguchi, K, and Miyazaki, K (2011). Downregulation of a newly identified laminin, laminin-3B11, in vascular basement membranes of invasive human breast cancers. Cancer science, 102, 1095-1100.

Rick, JW, Chandra, A, Dalle Ore, C, Nguyen, AT, Yagnik, G, and Aghi, MK (2019). Fibronectin in malignancy: Cancer-specific alterations, protumoral effects, and therapeutic implications. In Seminars in oncology (Elsevier), pp. 284-290.

Rodriguez-Pinilla, SM, Sarrio, D, Honrado, E, Moreno-Bueno, G, Hardisson, D, Calero, F, Benitez, J, and Palacios, J (2007). Vimentin and laminin expression is associated with basal-like 
phenotype in both sporadic and BRCA1associated breast carcinomas. Journal of Clinical Pathology, 60, 1006-1012.

Ross, JB, Huh, D, Noble, LB, and Tavazoie, SF (2015). Identification of molecular determinants of primary and metastatic tumour re-initiation in breast cancer. Nature Cell Biology, 17, 651-664.

Schneider, C. A., Rasband, W. S., \& Eliceiri, K. W. (2012). NIH Image to ImageJ: 25 years of image analysis. Nature Methods, 9(7), 671-675.

Swiatoniowski, G, Matkowski, R, Suder, E, Bruzewicz, S, Setta, M, Kornafel, J, Polozowski, A, and Surowiak, P (2005). E-cadherin and fibronectin expressions have no prognostic role in stage II ductal breast cancer. Anticancer Research, 25, 2879-2883.

Todd, JR, Ryall, KA, Vyse, S, Wong, JP, Natrajan, RC, Yuan, Y, Tan, A-C, and Huang, PH (2016). Systematic analysis of tumour cell-extracellular matrix adhesion identifies independent prognostic factors in breast cancer. Oncotarget, 7, 62939 .
Van Der Zee, J, Van Eijck, CH, Hop, WC, Biermann, K, Dicheva, B, Seynhaeve, AL, Koning, G, Eggermont, AM, and Ten Hagen, TL (2012). Tumour basement membrane laminin expression predicts outcome following curative resection of pancreatic head cancer. British Journal of Cancer, 107, 1153-1158.

Yi, W, Xiao, E, Ding, R, Luo, P, and Yang, Y (2016). High expression of fibronectin is associated with poor prognosis, cell proliferation and malignancy via the NF-kB/p53-apoptosis signaling pathway in colorectal cancer. Oncology Reports, 36, 3145-3153. 